\title{
JURISDICCIÓ I CONTROL DE LA NAVEGACIÓ A LA RIBERA I MAR DE BARCELONA
}

\author{
Maria Teresa FERRER I MALLOL \\ Departament d'Estudis Medievals \\ Institució Milà i Fontanals. CSIC
}

\section{JURISDICCIÓ A LA RIBERA I MAR DE BARCELONA}

Els ports, com els camins, foren posats pels Usatges de Barcelona sota l'especial salvaguarda del príncep al qual pertanyien. Els mercaders, com les altres persones, podien entrar, sortir i transitar tant pels camins com pels ports amb tota seguretat, sota l'empara de la pau i treva establerta pel príncep'. L'usatge «Omnes quippe naves" assegurà la seva protecció a totes les naus que entressin i sortissin de Barcelona, des del cap de Creus fins a Salou, i preveié contra els contraventors una multa del doble del dany causat ${ }^{2}$. Altrament, l'usatge «ltem statuerunt», que posà tot el terme de Barcelona, des de Castelldefels a Montcada, sota la pau i treva del príncep, inclogué també en aquest benefici les aigües territorials barcelonines fins a un límit de 12 llegües mar endins ${ }^{3}$. A partir dels anys 1060 i 1064, en els quals es creu que foren promulgats aquests usatges, totes les constitucions de pau i treva publicades periòdicament pels monarques catalans confirmaren aquelles concessions $i$, més endavant, les ampliaren.

L'atribució de la propietat de les platges i dels ports al príncep enllaçava amb la tradició romana. La propietat comportava, com a la pràctica romana, el dret a percebre impostos per l'ús de la riba marina i també l'administració de la justícia. A la ribera de

1 Usatges de Barcelona i Commemoracions de Pere Albert, ed. a cura de J. ROVIRA I ERMENGOL, Barcelona, ed. Barcino, 1933 (Col. «Els Nostres Clàssics»), usatge LIV, pp. 84-85. Cf. també l'edició a cura de J. BASTARDAS, Usatges de Barcelona. El codi a mitjan segle XII, Barcelona, 1984, Fundació Noguera, 1984, on aquest usatge porta el núm. 59.

2 Ibidem, usatge LII, p. 83. És el 57 a la segona edició indicada. 
Barcelona el comte posseïa, doncs, tots els drets d'imperi i jurisdicció i els econòmics. En ple exercici d'aquests drets veiem els comtes, des d'antic, i després els reis, atorgantne franquícia als ciutadans barcelonins i cedint-ne alguns a la catedral de Barcelona ${ }^{4}$.

En nom dels comtes de Barcelona i dels seus succesors, els reis de CatalunyaAragó, exercí la potestat i la jurisdicció marítima dins el municipi el veguer de Barcelona, que és, sembla, l'oficial més antic. Posteriorment, el batlle de Barcelona compartí alguna de les seves funcions i, més tard encara, a la darreria del segle XIII o al començament del XIV, el batlle general els arrabassà, a tots dos, els drets de tipus econòmic i el control de la navegaciós.

Des de mitjan segle XIII, els navegants i mercaders barcelonins veieren reconegudes les seves llibertats $i$ costums, entre els quals figurava la facultat de governar el tràfic marítim segons les seves antigues tradicions. L'any 1279 Pere el Gran creà el consolat de mercaders, que es fondria amb aquella primera organització de navegants i rebria la configuració definitiva, com a Consolat del Mar, a mitjan segle XIV. A poc a poc, els consellers de Barcelona i els cònsols de la mar anaren estenent la seva jurisdicció sobre el mar i la ribera a base de privilegis, aconseguits amb donatius o préstecs a la Corona en moments de dificultats econòmiques d'aquesta, en detriment de l'autoritat exercida pels oficials reials, tal com veurem més endavant ${ }^{6}$.

\section{JURISDICCIÓ MARÍTIMA EXERCIDA PER OFICIALS REIALS}

\section{El veguer $\mathrm{i}$ el batlle de Barcelona}

El 27 d'octubre de 1266, Jaume I descompartí les atribucions d'ambdós oficials per tal d'evitar els freqüents conflictes jurisdiccionals que s'originaven a causa de la coincidència de competències en nombrosos punts. Segons declarà llavors el monarca, corresponia al batlle la jurisdicció sobre el mar i la ribera de Barcelona, sobre els homicidis, baralles a mà armada, cops, bregues etc. que tinguessin lloc a la ribera marítima entre gent estrangera, malgrat que, en general, la jurisdicció criminal corresponia al veguer. Era també competència del batlle la redempció d'homes i embarcacions, obligats a servir la flota, i la vigilància de l'extracció de mercaderies vedades $^{7}$. El 1293 Jaume II confirmà aquesta distribució d'atribucions, insistint en la jurisdicció del batlle sobre el mar i la ribera ${ }^{8}$. El llibre de comptes del batlle de Barce-

3 Ibídem, usatge LIII, pp. 83-84. Porta el número 58 a la segona edició indicada.

4 A. DE CAPMANY I DE MONTPALAU, Memorias Históricas sobre la Marina, Comercio y Artes de la antigua ciudad de Barcelona, reed. anotada per E. GIRALTY RAVENTÓS I C. BATLLEY GALLART, Barcelona, 1961-1963, II, docs. 1, 3, 4, 5, 6, 7, 9, 16, 17, 33.

5 J. LALINDE, La jurisdicción real inferior en Cataluña ("corts, veguers, batlles»), Barcelona, 1966, pp. 46-57.

6 Cf. l'apartat Els cònsols del mar.

7 F. CARRERAS I CANDI, La ciutat de Barcelona, Barcelona, s.a., p. 531, n. 1374 i J. LALINDE, La jurisdicción real inferior, pp. 147 i 264.

8 lbídem. 
Iona publicat per J.M. Casas Homs, corresponent als anys $1375-1378$, recull un bon nombre de les multes que cobrà per infraccions d'aquesta mena: de la prohibició de treta de determinades mercaderies, com la farina; de la prohibició de fer-se a la mar, de varar barques o de moure-les sense autorització o per retenció de béns procedents de naufragis, que corresponien al rei ${ }^{9}$.

El control sobre l'armament de les naus per sortir en cors correspongué en un principi al veguer ${ }^{10} \mathrm{i}$, en absència seva, al batlle ${ }^{11}$, bé que després el batlle general absorbí aquesta funció. Fou també el veguer l'encarregat de perseguir i castigar els acusats d'exercir la pirateria, cosa natural atesa la seva major especialització en l'esfera de la justícia criminal. L'any 1381, per exemple, fou el veguer qui rebé l'ordre del rei de perseguir Roger de Montcada i Ximèn Pérez d'Arenós, que havien comès actes de pirateria contra embarcacions barcelonines ${ }^{12}$. Fou també el veguer qui rebé i custodià tres pirates genovesos, presos per Gerardo de Doni i portats a Barcelona l'any 1402. El rei volia que els jutgés el batlle, però hagué de consentir que fossin processats pel veguer, a petició dels «defenedors de la mercaderia». Sembla que el rei temia una sentència massa severa del veguer, que podia comprometre la negociació per renovar la pau amb Gènova ${ }^{13}$. És per causa de la competència de veguer en la pirateria que, entre els escassos processos conservats a l'antic arxiu del veguer, n'hi ha alguns de referents a preses marítimes ${ }^{14}$.

Però quan s'executava una marca o represàlia, era el batlle qui havia de rebre les mercaderies emparades per tal de poder procedir després a la indemnització dels damnificats. Es procedí així, almenys al començament del segle XIV, amb una marca contra genovesos ${ }^{15}$. A mitjan segle XV el batlle, o el sotsbatlle en nom seu, continuava intervenint en qüestions similars. Ho podem comprovar a través d'un procés davant la batllia general de Catalunya obert per la reclamació de mercaderies confiscades a

9 J.M. CASAS HOMS, Libre del batlle reial de Barcelona, Berenguer Morey (1375-1378), Barcelona, Fundació Salvador Vives Casajuana, 1976, pp. 39, 40, 66, 69, 70, 74, 92 etc.

10 L. KLUPFEL, El règim de la monarquia catalano-aragonesa a finals del segle XIII, "Revista Jurídica de Catalunya", 1930, p. 305.

11 A. DE CAPMANY, Memorias, il, pp. 66-67.

12 J.F. CABESTANY, Repertorio de cartas reales conservadas en el Instituto Municipal de Historia (1269-1458), "Documentos y Estudios", XVI. Materiales para la historia institucional de la ciudad, Barcelona, 1966, doc. 242.

13 ACA, C, reg. 2281, f. 152 r.-v. (1402, gener, 14), reg. 2175, f. 65 r.-v. (1402, febrer, 25), i reg. 2244, f. 164 v.-165 r. (1402, abril, 14). Comentat a M.T. FERRER I MALLOL, Antecedenti e trattative per la pace del 1402 fra la Corona catalano-aragonese e Genova: un tentativo per porre fine alla guerra in corsa, en curs de publicació al volum en memòria del Prof Giancarlo Sorgia, a cura de la Deputazione di Storia Patria per la Sardegna.

14 AHCB, Arxiu del veguer, «Sententiarum, 1, ff. 87 v.-100 r.: procés contra Ramon Ferrer, de Mallorca, que s'apropià d'una nau baionesa, que li havia estat confiada per Ramon de Sant Vicenç, que l'havia comprada a Modó al capità de l'armada catalana durant la guerra contra Gènova, i la vengué.

15 M.T. FERRER I MALLOL, Catalans i genovesos durant el segle XIII. El declivi d'una amistat, "Anuario de Estudios Medievales», $26 / 2$ (1996), p. 818. 
genovesos, transportades per una nau que fou aturada, quan passava a les envistes de Badalona, per un vaixell barceloní armat per Crisògon de Centelles, amb l'ajut d'un balener biscaí i d'un balener i un esquif a les ordres del sotsbatlle de Barcelona. Consta que la nau es reté al sotsbatlle i que fou aquest qui retingué les mercaderies. Crisògon de Centelles reclamà la seva part del botí pel seu paper decisiu en la presa ${ }^{16}$.

El batlle de Barcelona tingué també sota la seva salvaguarda les drassanes reials barcelonines, bé que qui se n'ocupava directament era el drassaner. Quan l'any 1375 Jaume de Cabanyals fou substituït per Bertran Sala en aquest càrrec, el batlle de Barcelona hagué d'encarregar-se de lliurar-li les drassanes amb l'inventari de tot el que contenien ${ }^{17}$. Alguns anys abans, el 1316, el batlle, juntament amb el veguer, havia rebut ordres del rei perquè obligués la marineria de la flota que s'havia organitzat l'any anterior a tornar tot allò que l'arsenal barceloní els havia prestat ${ }^{18}$. En aquest cas la intervenció del veguer es degué, segurament, a la seva major capacitat de coerció.

En canvi, a mitjan segle XIV, fou el batlle de Barcelona, juntament amb els consellers de la ciutat, qui nomenà capitans amb jurisdicció criminal i civil sobre les tripulacions de les naus, armades o no, que sortien de la ciutat en temps de guerra ${ }^{19}$.

\section{El batlle general de Catalunya}

Aquest càrrec, nascut a la darreria del segle XIII per a tenir cura de l'administració del Patrimoni reial, tingué una àmplia competència en afers marítims, ja que els interessos de la Corona en aquest camp eren molt importants ${ }^{20}$. Atorgà, per exemple, les llicències per a exportar mercaderies prohibides; una constitució de les Corts de Barcelona, del 1300, que suprimí la gabella de la sal, del blat i d'altres vitualles i donà llibertat de treta de vitualles i de tota mena de mercaderies amb qualsevol destinació que no fos terra d'enemics, n'exceptuà les següents: pega, sèu, quitrà, fusta, cànem, fil, eixàrcies, ferro, cavalls $i$ armes $i$ també blat $i$ vitualles en temps de carestia ${ }^{21}$; eren les mercaderies que la Santa Seu, des del 1179, havia prohibit de portar a terres islàmiques ${ }^{22}$

16 ACA, RP, Batllia, Processos, $14411 \mathrm{D}$.

17 A. DE CAPMANY, Memorias, II, doc. 303.

18 J. CABESTANY, Repertorio, doc. 13.

19 A. DE CAPMANY, Memorias, II, p. 205.

20 L. KLUPFEL, El règim de la monarquia catalano-aragonesa, “Rev. Jur, de Cat.», XXXV (1929), pp. 289-294; 297-298.

21 Cortes de los antiguos reinos de Aragón y de Valencia y Principado de Cataluña, publ. per la Real Academia de la Historia, Cortes de Cataluña, Madrid, 1901, I, pp. 171-172; A. M. ARAGÓ, Fletes de géneros prohibidos desde el puerto de Barcelona a la Liguria (1358-1409), Atti del ! Congresso Storico Liguria-Catalogna (Ventimiglia-Bordighera-Albenga-Finale-Genova, 1969), Bordighera, 1974, pp. 211-219.

22 J. TRENCHS, "De Alexandrinis" (El comercio prohibido con los musulmanes y el papado de Aviñón durante la primera mitad del siglo XIV), "Anuario de Estudios Medievales», 10 (1980) pp. 245249 y p. 255. IDEM, Les «Alexandrini» ou la désobéissance aux embargos conciliaires ou pontificaux contre les Musulmans, "Cahiers de Fanjeaux", 18 (1983). Islam et chrétiens du Midi (XIle-XIVe s.), pp. 177-182. 
i que, per tal d'evitar desviacions, eren controlades pel batlle general, tant en el port de sortida com en el de descàrrega, a través d'un albarà o certificat de l'autoritat local que calia presentar més tard al port d'origen. Dins dels ports de la Corona catalanoaragonesa aquesta certificació ja era una rutina però, quan el port de descàrrega previst era en un altre país, calia que el batlle demanés aquesta certificació a l'autoritat local. Trobem, per exemple, una carta al batlliu de Xipre per a demanar el certificat del descarregament de mel, alcofoll, ferret, cordes, llibants etc. que Joan Gatxa, patró de coca, portava a aquella illa ${ }^{23}$.

Les prohibicions papals de comerç amb els sarraïns s'havien alternat amb periodes d'una certa permissivitat, però a la fi del segle XIII la Santa Seu endurí la seva posició, particularment contra les terres de Sultanat de Babilònia després de la pèrdua d'Acre, el 1291.

Preveient, però, nombroses infraccions a aquesta prohibició, la Santa Seu autoritzà els bisbes a absoldre les excomunions en què incorrien els infractors, si el lucre s'usava per a la redempció de captius, defensa de la fe etc. El papat concedí, a més, als reis catalano-aragonesos la facultat d'autoritzar viatges a Alexandria i al sultanat de Babilònia en determinades condicions ${ }^{24}$. El batlle general fou l'encarregat de concedir aquestes llicències $i$ de rebre les quantitats estipulades per l'autorització i cobrà les multes corresponents en cas de transgressió. Són les llicències per a navegar a terra del sultà de Babilònia («parts vedades»).

Concedí, igualment, les llicències per a navegar en temps de guerra ${ }^{25}$. Durant un conflicte bèl.lic els vaixells podien ésser retinguts als ports catalans, bé perquè poguessin ésser incorporats a la flota reial, en cas necessari, bé per evitar un perill imminent quan les naus i galeres enemigues solcaven les aigües catalanes. L'any 1378, per exemple, les pretensions del duc d'Anjou al regne de Mallorca obligaren a armar vaixells per a la defensa dels regnes de la Corona catalano-aragonesa, que després s'usaren per a afers de Sicília i Sardenya perquè les amenaces del duc d'Anjou no arribaren a concretar-se. A causa d'aquest armament, Pere el Cerimoniós decretà, pel febrer de 1378, inhibició marítima general i prohibí que les embarcacions petites sortissin de les mars catalanes $i$ que les naus $i$ els vaixells grossos s'allunyessin de l'àrea de la Mediterrània occidental, a fi que estiguessin disponibles quan el rei els necessités ${ }^{26}$.

23 ACA, RP, Batllia, reg. 1056 (antiga classe 7ª $, H, 12$ ), f. 12 r.

24 Sobre el comerç prohibit amb el sultanat de Babilònia, encara que no es faci referència a les Ilicències expedides pel batlle general cf.: A. MASIÀ DE ROS, La Corona de Aragón y los estados del norte de África. Política de Jaime II y Alfonso IV en Egipto, Ifriquía y Tremecén, Barcelona, 1951, pp. 81-153; J. TRENCHS, “De Alexandrinis», pp. 237-320, i M. RIU, Nuevos datos sobre el comercio mediterráneo catalano-aragonés: el comercio prohibido con el Oriente islámico, «ll Congreso Internacional de Estudios sobre las culturas del Mediterráneo Occidental», Barcelona, 1978, pp. 315-328.

25 Cf. més endavant.

26 M.T. FERRER I MALLOL, La guerra d'Arborea alla fine del secolo XIV, en curs de publicació al volum de les Actes de «Giudicato d'Arborea e Marchesato di Oristano: proiezioni mediterranee e aspetti di storia locale. I Convegno Internazionale di Studi», Oristano, Istar, 1997. 
El batlle general s'encarregà de posar en pràctica la prohibició reial i, per exemple, ens consta que denegà la sortida al patró Francesc de Casasaja ${ }^{27}$.

També en aquests anys, entre 1380 i 1383, la revolta de Sardenya i la successió de Sicília, amb totes les complicacions internacionals que podien comportar, obligaren el monarca a posar traves a la liure circulació de sicilians i italians en general i les seves missives. Diversos patrons hagueren de prestar seguretat al batlle general que no portaven a Itàlia sicilians, genovesos, pisans ni italians en general, i tampoc les seves coses ni les seves cartes $^{28}$. També, a causa de la flota que el rei volia organitzar per intervenir a Sicília i a Sardenya, el batlle general prohibí la sortida de mariners l'any $1384^{29}$.

A la necessitat d'evitar topades amb l'estol franco-genovès contra Mahdia, respon la prohibició d'armar vaixells en cors el $1390^{30}$.

També competia al batlle la defensa de la costa mitjançant l'organització de talaies en llocs estratègics de la riba marina quan hi havia notícies de la presència de vaixells corsaris moros a les mars catalanes ${ }^{31}$.

El batlle general s'encarregà igualment, a vegades conjuntament amb l'almirall o el vicealmirall, de controlar l'armament de les naus en cors, exigir les fiances degudes i rebre després el quint de la presa, la dècima, la vintena part o la que correspongués al rei, segons els acords previs amb els armadors o en funció de la participació reial en l'empresa ${ }^{32}$. Atorgà també les llicències per a carregar armes de foc als vaixells $i$ per això els seus registres són una font preciosa per a conèixer els inicis de l'artilleria naval ${ }^{33}$. El batlle general rebé encara els guanys fets per les armades reials i també les multes imposades als corsaris que haguessin piratejat, els béns confiscats a l'enemic, els béns abandonats o trobats al mar o a la platja etc. ${ }^{34}$. Els consellers de

27 ACA, RP, Batllia, reg. 1065 (classe $7^{\mathrm{a}}, \mathrm{H}, 12$ ), f. 5 r.

28 Ibídem, ff. 8 v. (1380, juny, 30), ff. 30 r.-v., 31 r. i 32 r. -34 r. (1383, juliol, 16).

$29 \mathrm{Ibidem}, \mathrm{f} .55 \mathrm{v}$.

$30 \mathrm{lbidem}$, f. $70 \mathrm{r}$. Cf. sobre aquesta armada M.T. FERRER I MALLOL, Documenti catalani sulla spedizione franco-genovese in Berberia (1390), Miscellanea di Studi Storici, I, Genova, Fratelli Bozzi, 1969, pp. 213-261 (Collana Storica di Fonti e Studi diretta da G. Pistarino, 1).

31 ACA, RP, Batllia, reg. 1055, ff. 88 r.-89 r. (1394, agost, 22) i una ordre anterior, de 1382, estudiada per M.D. LÓPEZ PÉREZ, «Farons per a galiotes de moros»: Un ejemplo de organización de defensa costera en la Cataluña medieval, "Miscel.lània de Textos Medievals», 8, Barcelona, Departament d'Estudis Medievals, Institució Milà i Fontanals. CSIC, 1996, pp. 1-12.

32 A. DE CAPMANY, Memorias, II, pp. 254-257.

33 El 23 de junio de 1379, per exemple, trobem la llicència per carregar dues "ballestes de tro» a la nau de Francesc Saclosa, que anava a Alexandria; una altra del 6 de juliol per carregar una ballesta de tro a la coca de Francesc Fogassot, que anava a Sicília; una altra a favor de Pere Puigdespí per portar dues bombardes a Alguer; una altra, ja del 1381, per embarcar una bombarda a la nau de Bartomeu Vidal, que anava a Pisa, i una altra del 19 de juliol de 1382 per embarcar-ne dues a la de Berenguer Guerau; en ambdós casos eren per a la defensa de la mateixa nau: ACA, RP, Batllia, reg. 1065 (classe $7^{\mathrm{a}}, \mathrm{H}, 12$ ), ff. 2 v., 18 v., 21 r. i 26 r.

34 ACA, C, reg. 1546, f. 1 v.-2 v. Cf. també la reclamació per part del batlle general d'una caixa trobada a mar i d'altres béns trobats a la platja: ACA, RP, Batllia, reg. 857 (antiga classe $7^{\mathrm{a}}$, Ab, núm. 13), ff. II v. i 14 r. Cf. també RP, MR, reg. 1032, f. 51 v.: béns d'un naufragi esdevingut a Pals. 
Barcelona es queixaren en alguna ocasió d'abusos per part del batlle general en aquestes competències. Impugnaren, per exemple, l'any 1453, l'exacció indeguda d'impostos per l'extracció de coses prohibides en el cas del sèu o del quitrà destinat a la costa catalana, que segons ells era subjecta només a licència del batile i a la promesa del mercader de no portar-lo a llocs prohibits ${ }^{35}$.

La platja de Barcelona, doncs, estigué sota el superior control del batlle general, control exercit a través del batlle local, el sotsbatlle i els guardes de la mar, algun dels quals era especialitzat, per exemple, en treta o entrada de coses prohibides ${ }^{36}$. De la mateixa manera, les drassanes estigueren també sota vigilància seva, tant pel que respectava al personal -drassaner, mestres d'aixa, calafats etc.- com pel que respectava als treballs a realitzar —reparacions de l'edifici, dels vaixells que s'hi custodiaven, conservació d'armes $i$ eixàrcies etc. $-{ }^{37}$.

Com als batlles locals, pertocava també al batlle general la jurisdicció sobre els estrangers i no-cristians i la col.lecta dels impostos que els afectaven; per exemple, els drets de "porta" i de "mostalafia" que havien de pagar els sarraïns que sortien de Barcelona per a emigrar a països islàmics, complir la peregrinació a La Meca, etc. ${ }^{38}$; el tribut anual que pagaven els mercaders italians per la concessió del guiatge, abans de la creació de l'impost dels italians el $1402^{39}$ i el cobrament $O$ arrendament del dit impost i del dels alemanys posteriorment etc. ${ }^{40}$.

35 A. DE CAPMANY, Memorias, doc. 370 i A. GARCIA, Llibre del Consolat de Mar, Ill. 2. Diplomatari, doc, 48 .

36 El 1423 era guardià de les coses prohibides Arnau Matoses, que certificà que un patró de barca, Pere Ros, havia descarregat a la platja de Barcelona una dona napolitana, anomenada Brígida, esposa de Bartomeu de Vilafranca, que hi havia pujat a Dénia: ACA, RP, Batllia, reg. 1080, f. 2 r. (1423, març, 27). Com és ben sabut, l'embarcament de dones era controlat estrictament a tot el litoral català.

37 ACA, C, reg. 1546, f. 33 r.-34 r.

38 D. ROMANO, Musulmanes residentes y emigrantes en la Barcelona de los siglos XIV-XV, «Al Andalus", XLI (1976), pp. 49-87, i M. T. FERRER I MALLOL, Els sarraïns de la Corona catalano-aragonesa en el segle XIV. Segregació i discriminació, Barcelona, Institució Milà i Fontanals. CSIC, 1987, pp. 137-183, i L'emigració dels sarrains residents a Catalunya, a Aragó i al Pais Valencià durant la Baixa Edat Mitjana, a L'expulsió dels moriscs. Conseqüències en el món islàmic i en el món cristià. Actes del Congrés Internacional «380 Aniversari de l'Expulsió dels Moriscs (Sant Carles de la Ràpita, 1990), Barcelona, Generalitat de Catalunya, Departament de Cultura, 1994, pp. 19-26.

39 M. T. FERRER I MALLOL, Mercanti italiani in terre catalane: gli alessandrini (1394-1408), «Rivista di Storia, Arte e Archeologia per le Province di Alessandria e Asti», LXXV (1966), pp. 5-44, i Els italians a terres catalanes (segles XII-XV), «Anuario de Estudios Medievales», 10 (1980), pp. 401-404, i ACA, RP, MR, reg. 1015 , f. 58 r., reg. 1016, f 49 r., 1023, f. 50 r., reg. 1026, f. 70 r. etc.

40 ACA, RP, MR, reg. 1069 , f. 49 v. etc. Sobre el dret dels alemanys cf. M. MITJÀ SAGUÉ, Dificultades de la industria y comercio alemanes para abrirse paso en Barcelona hasta 1410, "Spanische Forschungen der Görresgesellchaft. 1 Reihe: Gesammelte Aufsärtze zur Kulturgeschichte Spaniens», XIII (1958), pp. 188-228 i El comercio y la industria alemanes en Barcelona de 1410 a 1420, Homenaje a Johannes Vincke, I, Madrid, CSIC, 1962-1963, pp. 285-319; C. CARRÈRE, Barcelona 1380-1462. Un centre econòmic en època de crisi, Barcelona, Curial, 1977, I, pp. 367-375, II, p. 48. 
En alguns períodes el batlle general fou privat de part d'aquestes amplíssimes competències marítimes; almenys ho fou, entre 1358 i 1363, pel «conservador de les drassanes", càrrec creat per Pere el Ceremoniós a favor de Bonanat Descoll. Sembla, però, que, si bé aquest percebé per ordre del rei els emoluments derivats de tot el que era "factum maris", ho féu a través del batlle general, que continuà administrant aquests afers. De fet, només les qüestions realment pròpies de les drassanes es degueren escapar del tot al batlle general que, malgrat tot, recuperà la seva plena jurisdicció marítima a la mort de Bonanat Descoll ${ }^{41}$.

És, doncs, dins la documentació procedent de l'oficina del batlle general on es troben les sèries més riques referents al tràfic marítim, especialment a la que antigament es conservava a la classe $7, \mathrm{H}$, que conté els registres dels albarans per a l'exportació de mercaderies prohibides, les liicències per a navegar en temps de guerra o de perill, les seguretats prestades pels mariners i altres navegants de vaixells armats, el control sobre l'exportació de blat etc. ${ }^{42}$.

Contenen també notícies d'interès els registres de cartes del batlle ${ }^{43}$, igual com els processos de batllia, on es troba documentació sobre plets entre el fisc reial i particulars pel quint reial de les preses corsàries, despulles marítimes etc. ${ }^{44}$.

\section{L'almirall, el vicealmirall, el capità general i altres càrrecs relacionats amb la marina de guerra}

L'almirall era un de sol per a tots els regnes de la Corona d'Aragó i era, després del rei, el cap suprem de la flota de guerra, bé que el segle XIII i el primer terç del XIV el nom d'almirall s'aplicà amb freqüència a tots els capitans de flota ${ }^{45}$; ocupà sempre el càrrec d'almirall del rei un membre de l'alta noblesa catalana. Els nomenaments eren generalment a beneplàcit del monarca fins a mitjan segle XIV. El de Ramon de Peralta, del 1336, tingué ja caràcter vitalici, bé que fou revocat perquè no acudí a la convocatòria reial el 1337, quan es trobava a Sicília; els de Jofre Gilabert de Cruilles i de Pere de Montcada, que el substituïren, foren de nou a beneplàcit. Els nomenaments posteriors, en canvi, foren vitalicis ${ }^{46}$.

Entre les atribucions del càrrec figurava la de poder enrolar gent per a l'armada, la qual quedava sota la seva jurisdicció civil i criminal des de quinze dies abans de la

41 ACA, C, reg. 1546, ff. 1 v.-2 v.; 33 r. -34 r.

42 ACA, secció del Reial Patrimoni, subsecció del Mestre Racional, registres de càrrec i data de la Batllia General de Catalunya, regs. 967-1125, i subsecció de la Batllia, antiga classe 7 $, \mathrm{a}, \mathrm{H}$.

43 Per exemple, ACA, RP, Batllia, reg. 857 (antiga classe $7^{\mathrm{a}}, \mathrm{Ab}, 13$ ), que conté llicències per portar blat a Sicília i Sardenya, ff. 1 r. y 5 r.; compareixença d'un patró barceloni, que havia estat retingut a Mallorca per ordre del rei: ff. 2 v. -3 r. (1398, abril, 10).

44 ACA, RP, Batllia, Processos antics.

45 R. GALLOFRÉ I J. TRENCHS, Almirantes y vicealmirantes de la Corona de Aragón (11181462), «Miscel.lània de Textos Medievals», 5 (1989), docs. 18, 19, 22, 23 etc.

46 R. GALLOFRÉ i J. TRENCHS, Almirantes y vicealmirantes de la Corona de Aragón, docs. 46, $52,60,64,131,144$ y 151. 
sortida de la flota fins a quinze dies després de la fi del seu servei, tant en terra com en mar. Quedaven també sota la seva superior jurisdicció els armadors en cors i els seus homes, igual com les flotes defensives organitzades pels municipis ${ }^{47}$, bé que cal fer notar que la ciutat de Barcelona aconseguí freqüentment l'exempció d'aquesta jurisdicció per a les seves armades ${ }^{48}$, que incloïa a vegades explícitament la lliure disposició de tot el botí, compresa la part, suposem, deguda a l'almirall ${ }^{49}$. Algun almirall, com Pere de Montcada, el 1340, fou autoritzat a armar dues galeres quan volgués, amb càrrec a la hisenda reial ${ }^{50}$.

Tingué també l'almirall la jurisdicció civil i criminal sobre el personal que treballava a les drassanes reials, durant la construcció, reparació o armament d'una flota, és a dir, els mestres de galeres, mestres d'aixa, calafats, obrers etc. ${ }^{51}$, i sembla que tingué igualment competències sobre les naus i eixàrcies que s'hi conservaven ${ }^{52}$; en aquest punt resulta difícil determinar quines eren les atribucions del batlle reial i quines les de l'almirall. Lògicament, el primer hauria hagut de tenir cura només de la part administrativa $i$ financera $i$ el segon, de la part militar; però els límits de les competències foren sempre imprecisos $i$ els conflictes jurisdiccionals entre els diferents oficials reials $i$ entre aquests i els municipals en qüestions marítimes foren abundants.

D'altra banda, l'almirall, igual que el batlle general, exercí també el control de la navegació, imposant prohibicions $\mathrm{i}$ atorgant llicències per a navegar, exigint seguretats als navegants etc. en temps de guerra; unes atribucions, però, que li foren discutides pels consellers de Barcelona ${ }^{53}$. Els nomenaments d'almirall no solen especificar aquesta prerrogativa, mentre que sí que ho fa algun nomenament de capità general ${ }^{54}$.

47 A. DE CAPMANY, Memorias, II, doc. 84; L. KLUPFEL, El règim de la monarquia catalanoaragonesa, «Rev. Jur. de Cat.», 1930, p. 301; R. GALLOFRÉ i J. TRENCHS, Almirantes y vicealmirantes de la Corona de Aragón, docs. 46, 52, 60, 64, 131, 144 y 151.

48 A. DE CAPMANY, Memorias, II, docs. 44, 126, 136, 155, 282, 287, 288; R. GALLOFRÉ i J. TRENCHS, Almirantes y vicealmirantes de la Corona de Aragón, docs. 22, 87, 142, 146 i 147.

49 A. DE CAPMANY, Memorias, II, docs. 126 i 288.

50 R. GALLOFRÉ i J. TRENCHS, Almirantes y vicealmirantes de la Corona de Aragón, doc. 64.

51 R. GALLOFRÉ i J. TRENCHS, Almirantes y vicealmirantes de la Corona de Aragón, docs. 46, $52,60,64,131,144$ i 151.

52 El 23 de juliol de 1315, Jaume II ordenà al guardià de les drassanes de València que lliurés al prior del convent de predicadors d'aquesta ciutat una galera vella, que ja no es pogués reparar. L'almirall Carròs s'hi oposà pretextant que li corresponia pel seu càrrec, però el rei negà que pogués quedar-se* la: J.E. MARTÍNEZ FERRANDO, Jaime // de Aragón. Su vida familiar, II, doc. 179. L'incident revela que, malgrat que no li corresponia la propietat de les galeres velles, controlava el material naval conservat a les drassanes. Els nomenaments d'almirall no solen especificar la competència sobre el material naval, mentre que sí que ho fa un dels nomenaments de capità general: A. DE CAPMANY, Memorias, II, doc. 203 i R. GALLOFRÉ i J. TRENCHS, Almirantes y vicealmirantes de la Corona de Aragón, doc. 120.

53 ACA, C, reg. 1227, f. 65 r.-v.

54 A. DE CAPMANY, Memorias, II, doc. 203; R. GALLOFRÉ i J. TRENCHS, Almirantes y vicealmirantes de la Corona de Aragón, doc. 120. 
A diferència del que s'esdevingué a Castella, els almiralls catalans no sembla que arribessin a tenir altres pretensions jurisdiccionals sobre el comerç marítim ${ }^{55}$.

Pertocava a l'almirall, com a retribució del seu càrrec, el vintè de la part corresponent al rei en el botí pres per la flota, llevat dels vaixells i eixàrcies que es guanyessin, que eren exclusivament per al rei. El nomenament de fra Romeu de Corbera, del 1420, assigna, però, a l'almirall la cinquena part de la porció de botí pertanyent al monarca; a més corresponia a l'almirall el trentè, el vintè i en algun cas, ja del segle XV, fins i tot la dècima part dels moros presos, mentre que els captius cristians eren tots per al rei. L'almirall, a més, des del dia en què començava la preparació d'una flota fins que no desarmava, cobrava a càrrec de la cort 30 sous barcelonesos diaris, més tard 40 sous diaris $i$, el segle $X V, 60$ sous diaris per a les seves despeses, més un petit impost sobre cadascun dels homes enrolats a la flota ${ }^{56}$.

A cadascun dels regnes marítims, Catalunya, València i Mallorca, hi hagué un vicealmirall, nomenat generalment entre els representants més destacats de l'estament ciutadà i mercantil, que exercí les atribucions de l'almirall en absència d'aquest. El de Catalunya residí habitualment a Barcelona. Galceran Marquet, Guillem Morey i Francesc d'Aversó foren alguns dels barcelonins que ocuparen aquest càrrec durant el regnat de Pere el Cerimoniós i tingueren una intervenció destacada tant en el control de la guerra en cors contra els genovesos com en la regulació de la navegació. De Guillem Morey sabem que intervingué, juntament amb el batlle Pere Sacosta, en la interpretació de les ordinacions reials sobre la navegació, l'any $1357^{57}$. Francesc d'Aversó arribà a ocupar el càrrec d'almirall i de capità general, de manera interina, mentre tots dos càrrecs estigueren vacants ${ }^{58}$. Més endavant, tenim constància que el 1393 ocupà aquest càrrec Galceran Marquet, també barceloní i fill del seu predecessor del mateix nom ${ }^{59}$.

Sembla que almiralls i capitans generals tenien tendència a ignorar els vicealmiralls i a confiar les tasques que ells no podien portar a terme a lloctinents de la seva confiança, per això Pere el Cerimoniós puntualitzà que, si la flota es dividia, el vicealmirall que hi fos present s'havia de fer càrrec d'una de les parts de l'estol i, si l'almirall o el capità general eren absents, el vicealmirall els havia de substituir en tot, llevat del salari60.

55 A. GARCIA I SANZ, Llibre del Consolat de Mar, III. 1, p. 125. Cf. també J. MARTÍNEZ GlJÓN, La jurisdicción marítima en Castilla durante la baja Edad Media, «Historia» (Universidad Católica de Chile, 1969, pp. 313-315 i 319.

56 R. GALLOFRÉ i J. TRENCHS, Almirantes y vicealmirantes de la Corona de Aragón, docs. 46, $52,60,64,131,144$ i 151.

57 A. DE CAPMANY, Memorias, doc. 177, i ACA, RP, Batllia, reg. 1056 (antiga classe $7^{\mathrm{a}} \mathrm{H}$ ), f. 23 r. (1357, febrer, 18).

58 A. DE CAPMANY, Memorias, II, docs. 171, i 177; J.F. CABESTANY, Repertorio, doc. 141; R. GALLOFRÉ i J. TRENCHS, Almirantes y vicealmirantes de la Corona de Aragón, docs. 65, 106, 107, 143 i 145.

59 M.T. FERRER I MALLOL, Lluites de bàndols a Barcelona en temps del rei Marti l'Humà, "Estudis d'Història Medieval», 1. Estudis dedicats a Ferran Soldevila, Barcelona, Institut d'Estudis Catalans, 1969 , pp. 75-94.

60 R. GALLOFRÉ i J. TRENCHS, Almirantes y vicealmirantes de la Corona de Aragón, doc. 109. 
La jurisdicció del vicealmirall fou també objecte de discussió. Sabem que l'any 1443 Alfons el Magnànim denegà al vicealmirall Antoni Bertran la facultat d'ajusticiar un mariner per delictes comuns i comunicà la seva decisió als consellers de Barcelona, que s'hi devien haver oposat per considerar-ho competència dels cònsols del mar ${ }^{61}$. Els cònsols de Mallorca havien aconseguit una provisió reial, l'any 1393, que limitava la jurisdicció del vicealmirall del regne insular a les armades organitzades pel rei 0 pels infants i al seu personal, mentre que els armaments navals fets per particulars, inclosos els que tenien una finalitat militar, i el seu personal eren de la jurisdicció del Consolat de Mar i dels altres oficials ordinaris als quals correspongués. A Catalunya es plantejà també una qüestió similar, l'any 1425 , quan l'advocat fiscal del rei reclamà una consulta al monarca sobre a qui pertocava la jurisdicció d'una causa entre un patró de nau i els homes que havia enrolat. De moment, el veguer de Barcelona pronuncià una sentència atribuint-la als cònsols del mar; més endavant, l'any 1443, el rei resolgué que en aquests casos la jurisdicció corresponia als cònsols del mar, com a Mallorca, és a dir, que el vicealmirall no tindria jurisdicció en els armaments organitzats per particulars ni en el seu personal ${ }^{62}$. La mateixa provisió reial establí que ni el vicealmirall ni l'almirall no podrien exigir un impost de dos sous ni altres taxes a cadascun dels homes que s'enrolaven a les naus, galeres i altres vaixells que s'armaven a Barcelona, tal com s'exigia fins llavors ${ }^{63}$. Hem comentat ja que l'almirall tenia dret a percebre un impost sobre els homes que s'enrolaven i suposem que era en nom seu que el vicealmirall l'exigia. Sembla clar que el resultat d'aquestes disputes fou una sensible disminució de les competències jurisdiccionals de l'almirall i del vicealmirall.

Des del moment que el càrrec d'almirall fou concedit de manera vitalícia, podia donar-se el cas que qui l'ocupés no estigués en condicions d'assumir el comandament efectiu de la flota en temps de guerra. Per això es confià aquesta tasca a una persona amb experiència marítima, per a la qual es creà el càrrec de capità general de l'armada reial, al qual foren atribuïdes moltes de les competències de l'almirall ${ }^{64}$. Només cal examinar les concedides a Gilabert de Cruïlles l'any 1375: jurisdicció criminal sobre els homes enrolats a larmada, control sobre els armaments en cors, vigilància sobre les drassanes, amb poders per a destituir i reemplaçar-ne els funcionaris, i la mateixa cosa respecte als ports i platges i els funcionaris respectius $i$, finalment, potestat per a decretar prohibicions generals de navegar quan s'organitzessin flotes reials per a atacar vaixells enemics en aigües catalanes ${ }^{65}$. En algun cas el nomenament tingué

61 Ibidem, doc. 152.

62 A. GARClA, Libre del Consolat de Mar, III. 2, pp. 126-127 y docs. 121, 25, 43 y 44. Cf también A. de CAPMANY, Memorias, II, doc. 339.

63 A. GARCIA, Llibre del Consolat de Mar, III. 2, doc 43.

64 R. GALLOFRÉ i J. TRENCHS, Almirantes y vicealmirantes de la Corona de Aragón (11181462), "Miscel.lània de Textos Medievals», 5 (1989), pp. 118-119.

65 A. de CAPMANY, Ordenanzas de las armadas reales de la Corona de Aragón, aprobadas por el rey D. Pedro IV, año de MCCCLIV, Madrid, 1787, pp. 144-147, i Memorias, II, doc. 203, y R. GALLOFRE i J. TRENCHS, Almirantes y vicealmirantes de la Corona de Aragón, docs. 88, 93, 104 y 120. 
límits temporals: quatre mesos, per exemple, per a Ponç de Santa Pau, i una part diferent del botí, la meitat d'un terç del total en aquest mateix cas $^{66}$.

Càrrecs menors relacionats amb la flota eren els de l'algutzir de la mar i l'escrivà de les armades; el primer era el cap de la policia militar marítima; el segon era l'encarregat de l'administració de la flota: dels comptes de les despeses i dels guanys derivats de les preses fetes ${ }^{67}$.

De caràcter mixt militar i civil eren els funcionaris de les drassanes: el conservador general de les drassanes reials, al qual ja ens hem referit, càrrec efímer lligat a la persona de Bonanat Descoll ${ }^{68}$; el drassaner general en cadascun dels regnes ${ }^{69}$, amb els seus subordinats, els drassaners, els quals tenien cura del dipòsit d'armes, rems, veles i eixàrcies existents als arsenals i del possible lloguer als vaixells mercants, de la conservació i reparació de les galeres reials i de la supervisió de la seva construcció. A les seves ordres es trobaven els mestres d'aixa, un dels quals era el mestre d'aixa major, que dirigia les construccions navals ${ }^{70}$, els calafats, fusters capmestres, fusters comuns, serradors, traginers etc. ${ }^{71}$.

\section{JURISDICCIÓ MARÍTIMA EXERCIDA PER LES AUTORITATS MUNICIPALS}

\section{Els cònsols del mar}

Des d'antic, els patrons i mercaders més entesos en les coses del mar, a Barcelona els anomenats "prohoms de ribera", que regiren el barri marítim barceloní a la segona meitat del segle XIII, establiren amb les seves ordinacions $i$ amb les seves interpretacions dels costums marítims antics un conjunt de lleis per les quals es regí la marina mercant barcelonina i catalana en general i que, amb el temps, quedaren consolidades en el Llibre del Consolat de Mar72. Probablement, des d'antic també, els

66 R. GALLOFRÉ i J. TRENCHS, Almirantes y vicealmirantes de la Corona de Aragón, doc. 88.

67 El 1301 era algutzir de les armades Bonanat d'Om (o Salom): ACA; C, reg. 199, f. 3; el 1375 fou nomenat Miquel Corral, que fou recomanat pel rei a l'almirall Hug de Cardona: reg. 1404, f. 128, i el 1396 ho foren Llorenç Pipo i Ramon Brull, reg. 2209, ff. 27 r.-v. i 36 r.-v.

68 ACA, C, reg. 1546, ff. 1 r. -2 v.

69 Testimonia la seva existència una àpoca signada per Bartomeu Sala, drassaner de Barcelona, l'11 de maig de 1403, a favor de Bernat de Condamina, drassaner general de Catalunya i ciutadà de Barcelona: AHPB, not. Joan Gasset, man. de 1401-1404.

70 ACA, C, reg. 2121 , f. 30 r.

71 A. de CAPMANY, Memorias, II, doc. 205.

72 A.de CAPMANY, Memorias, II, doc. 14. J.M. FONT I RIUS, La universidad de prohombres de Ribera de Barcelona y sus ordenanzas maritimas (1258), a Estudis sobre els drets i institucions locals en la Catalunya medieval. Col.lectànea de treballs del Prof. Dr. J.M. Font i Rius amb motiu de la seva jubilació acadèmica, Barcelona, 1985, pp. 690-691; A. GARCIA, Llibre del Consolat de Mar, III.1. Estudi jurídic, pp. 73-75 i III.2. Diplomatari, doc. 1 pp. 9-10; C. BATLLE I GALLART, Els prohoms de Ribera de Barcelona i llurs atribucions en matèria urbanística (segona meitat del segle XIII) a El Pla de Barcelona i la seva història, Barcelona, 1984, p. 160; M.T. FERRER I MALLOL, Sobre els origens del Consolat de Mar a Barcelona el 1279 i sobre els consols d'Ultramar a bord de vaixells. Un exemple de 1281, "Anuario de Estudios Medievales", 23(1993), pp. 141-144. 
mercaders i navegants solucionaren els petits conflictes de tipus civil sorgits entre ells segons aquestes mateixes lleis consuetudinàries, acudint només a les autoritats reials per a afers de major importància.

Fou una tendència constant de l'estament mercantil barceloní i de les autoritats municipals la d'anar absorbint a poc a poc la jurisdicció civil i fins i tot criminal a la ciutat $i$ al port, a fi d'aconseguir una autonomia dels oficials reials, cosa que en part aconseguiren mitjançant privilegis pagats a bon preu.

L'autonomia judicial dels mercaders i navegants barcelonins féu un gran pas quan, el 20 de juny de 1279, Pere el Gran creà una nova magistratura municipal, la dels cònsols del mar ${ }^{73}$, que enllaçava amb la dels prohoms de Ribera. El Consolat, però, no fou establert en la seva forma definitiva $\mathrm{i}$ amb tots els seus privilegis fins el 21 de febrer de 1348 per Pere el Cerimoniós ${ }^{74}$.

L'elecció dels cònsols del mar i del jutge de les apel.lacions, creat per aquesta última disposició, correspongué als consellers $i$, el segle $\mathrm{XV}$, a més als representants dels quatre estaments ciutadans: ciutadans honrats, mercaders, artistes i menestrals ${ }^{75}$.

El procediment judicial seguit pels cònsols i pel seu jutge era breu i simple i en quedava descartada tota intervenció dels juristes. Les seves sentències no tenien apel-lació ni recurs a cap altre tribunal, ni tan sols al del mateix rei. El monarca hagué de reafirmar, en nombroses ocasions i a instàncies dels consellers de Barcelona i dels cònsols del mar, aquest privilegi, ja que sovint els que havien perdut la seva causa davant dels cònsols aconseguien presentar-la en apel-lació davant del rei ${ }^{76}$.

A fi d'aconseguir una autonomia completa en el seu tribunal del consolat, la ciutat de Barcelona i els seus representants hagueren de lluitar per mantenir incòlume l'al.ludit privilegi de inapel.labilitat de les seves sentències, i per impedir les intrusions dels funcionaris reials, la jurisdicció dels quals havien substituït, el batlle de Barcelona, en algunos $\operatorname{casos}^{77}$, el veguer de Barcelona ${ }^{78}$, el governador de Catalunya ${ }^{79}$ i fins i tot l'almirall i el vicealmirall, en altres $\operatorname{casos}^{80}$.

A poc a poc els cònsols del mar i el jutge d'apel.lacions anaren augmentant la seva jurisdicció i els instruments per a exercir-la. A més de tenir competència sobre tots els afers de caràcter civil relacionats amb la marina mercant, els cònsols foren capacitats per Joan I, el 1394, per a elegir un consell de deu a vint mercaders $\mathrm{i}$ juntament amb ells ocupar-se de la defensa del comerç, de les llicències de marques, dels impostos

73 A. de CAPMANY, Memorias, I, p. 339, I II, doc. 28. Segons C. CARRÈRE, Barcelona, I, p. 35, aquest fet s'esdevingué el mes de juliol de 1272.

74 A. de CAPMANY, Memorias, II, doc. 155.

75 C. CARRÈRE, Barcelona, l, pp. 36-38.

76 A. de CAPMANY, Memorias, II, docs. 213 i 263. C. CARRÈRE, Barcelona, I, pp. 38-45.

77 A. de CAPMANY, Memorias, II, docs. 170 i 212 i A. GARCIA, Llibre del Consolat de Mar, III.1, pp. 79 i 106-107 i III.2, doc. 8.

78 A. GARCIA, Llibre del Consolat de Mar, III.1, pp. 78-79 i III. 2, doc. 6.

79 A. de CAPMANY, Memorias, doc. 370 i A. GARCIA, Llibre del Consolat de Mar, III. 2, doc. 48.

80 A. de CAPMANY, Memorias, doc. 339 i A. GARCIA, Libre del Consolat de Mar, III. 2, docs. 43 i 44 . Cf. abans, nota 61 . 
etc. i, si els semblava convenient, elegir dues persones que s'ocupessin d'aquests afers i donar-los poders. Per a sostenir les despeses de la defensa marítima foren autoritzats a imposar i administrar l'impost del pariatge, en el moment i durant el temps que els semblés oportú ${ }^{81}$.

Consta que els cònsols intervenien com a jutges i mediadors en les queixes presentades per estrangers contra corsaris catalans i que s'encarregaven de la devolució dels béns robats i de la indemnització de les víctimes ${ }^{82}$. Per exemple, l'any 1398, els cònsols del mar de Barcelona havien negociat un acord amb el castellà Juan Alfonso de Moya i altres damnificats pel corsari Joan Álvarez d'Espejo, d'Oriola, pel qual aquests havien renunciat als seus drets a favor del Consolat a canvi d'una indemnització que aquesta institució es comprometé a fer-los arribar; els cònsols havien pres aquesta decisió per tal d'evitar que continués a Castella l'execució de la marca contra catalans que els damnificats havien obtingut i que havia perjudicat ja a diversos mercaders de Barcelona i de València; els cònsols havien demanat al rei poder recuperar aquests diners a través de les multes i execucions de béns imposades al corsari; per això Martí l'Humà manà al batlle general de València dellà Xixona, Joan de Roncesvalls, que lliurés aquests diners als cònsols de Barcelona; però Joan Álvarez d'Espejo era persona poderosa a aquella comarca; en un primer moment, malgrat els manaments de la reina Maria i les demandes presentades pels damnificats, el batlle no havia fet res contra el corsari bé que, per salvar l'honor, havia assegurat la suma pagada pels cònsols sobre els seus propis béns, suma que no havia pas abonat; després, davant la insistència del rei Martí, havia iniciat execucions de béns contra el culpable i els seus fiadors, els Togores, que havien recorregut contra aquesta mesura; a més havia fet jutjar Joan Álvarez d'Espejo, que havia estat condemnat a mort; el rei manà que el batlle executés la sentència i decapités el corsari, però abans calia capturar-lo, cosa que no fou possible; qui, en canvi, fou pres a Oriola fou el notari valencià, Ramon de Tolosa, procurador dels cònsols del mar de Barcelona, que fou insultat, acusat de falsari i traïdor i gairebé agredit pel germà del corsari, Llop Álvarez d'Espejo; el procés d'apel-lació presentat pel corsari hagué d'ésser portat a Alacant, com a lloc neutral, ja que les pressions eren massa fortes a Oriola i el procurador dels cònsols corria perill de mort ${ }^{83}$.

No és l'únic cas que coneixem d'intervenció dels cònsols en la indemnització de preses marítimes, bé que és el més accidentat. També, l'any 1400, els cònsols s'havien de fer càrrec de tots els béns que el corsari castellà Sancho de Boitrón tenia a Barce-

81 A. DE CAPMANY, Memorias, docs. 249 i 250; C. CARRĖRE, Barcelone, I, pp. 51-70.

82 A. de CAPMANY, Memorias, II, docs. 264, 265, 266; SMITH, The Spanish guild merchant. $A$ History of the Consulado, p. 49 , n. 90.

83 A. DE CAPMANY, Memorias, II, docs. 264 i 266 i ACA, C, reg. 2116 , ff. 34 v. -35 r. i 158 v. -160 r. (1398, abril, 1 i agost, 23), i reg. 2119 , ff. 97 r.-99 v. i reg. 2121, f. 105 r.-v. (1399, febrer, 17). Cf. sobre aquesta qüestió M.T. FERRER I MALLOL, La Batlia General de la part del regne de València dellà Xixona, "Anales de la Universidad de Alicante», 6 (1987), p. 295. 
lona, per tal de procedir a la devolució dels que havia robat o a la indemnitzación ${ }^{84}$. Uns quants anys després, el lloctinent del mestre de Rodes, de l'orde de l'Hospital, adreçà als cònsols del mar, directament, una requesta d'indemnització per la presa d'una nau genovesa que portava béns de ciutadans de Rodes pel corsari català Francesc Josep; aquesta interpel.lació directa s'explica perquè el fet s'esdevingué el 1411, en ple interregne ${ }^{85}$.

L'any 1395 els fou concedida autoritat sobre el gremi de barquers de la platja de Barcelona en tot allò que respectava als salaris que aquests darrers exigien per la descàrrega dels vaixells en els moments de temporal ${ }^{86}$; i el 1397 , sobre els canviadors, a fi de fer-los complir les ordinacions dictades sobre el seu ofici pels consellers de Barcelona $^{87}$.

Però l'ampliació més important de la seva jurisdicció l'obtingué el consolat de Barcelona el 1401, any en què, a conseqüència del Parlament de Tortosa i Barcelona del 1400 , el rei Martí li concedí la competència en tots els afers mercantils i no solament en els relacionats amb el mar: canvis, societats, contractes etc. ${ }^{88}$. Era una conquesta decisiva que confirmava i ampliava els privilegis concedits al consolat per Pere el Cerimoniós i que confirmava per a aquests afers l'exclusivitat i la inapel-labilitat de les sentències del consolat.

Posteriorment, Alfons el Magnànim estengué encara la jurisdicció del consolat als processos de fallida, deutes dolosos etc., tant en camp civil com criminal; la concessió. era important perquè la jurisdicció criminal pertocava ordinàriament als tribunals reials ${ }^{89}$ i, l'any 1444, el mateix monarca, usant el precedent dels privilegis del consolat de Mallorca, declarà que corresponia als cònsols decidir les qüestions relacionades amb l'armament de naus, galeres i llenys i que, per tant, l'almirall i el vicealmirall no podien exigir un impost als homes enrolats en elś vaixells que s'armaven a Barcelona, principalment per a exercir el comerç, tal com aquells ho feien, ni tampoc no havien d'intervenir en les causes civils d'aquesta gent. De fet l'autoritat de l'almirall i del vicealmirall quedava notablement disminuïda, ja que les causes civils quedaven reservades als cònsols $\mathrm{i}$ les criminals ho eren al "juí de prohoms» de Barcelona ${ }^{90}$. Només les causes relatives a la gent enrolada en les armades reials continuaren depenent exclusivament de la seva jurisdicció.

84 M.T. FERRER I MALLOL, Documents sobre el Consolat de castellans a Catalunya i Balears, "Anuario de Estudios Medievales", 1 (1964), p. 601 i doc. 5.

85 M.T. FERRER । MALLOL, Una flotta catalana contro i corsari nel Levante, a Oriente e Occidente tra Medioevo ed Età Moderna. Studi in onore di Geo Pistarino, Gènova, Glauco Brigati, 1997, p. 353.

86 A. de CAPMANY, Memorias, II, doc. 257.

87 Ibidem, doc. 260.

88 Ibidem, doc. 268.

$89 \mathrm{Ibidem}$, doc. 291.

90 Ibidem, doc. 339 i A. GARCIA, Libre del Consolat de Mar, III.1, pp, 126-127 i docs. 121, 25, 43 y 44 . Cf. abans, la nota 50 . 
També, pel que fa a la capacitat executiva, els cònsols de Barcelona havien aconseguit notables progressos. En un principi aquesta capacitat era limitada; si bé els cònsols podien executar confiscacions i empares per mitjà dels seus saigs, havien de recórrer en moltes ocasions a l'autoritat del veguer o del batlle per a fer complir algunes de les seves sentències i els càstigs imposats als que desobeïen els seus manaments. A causa de la seva limitada capacitat executiva, els manaments dels cònsols eren poc temuts, per la qual cosa fou un constant objectiu seu aconseguir més independència executiva. Les concessions més importants en aquest camp les obtingueren d'Alfons el Magnànim; el 1444, aquest monarca autoritzà els cònsols a executar les sentències penals que decretessin, tal com ho feien el batlle i el veguer en les seves jurisdiccions respectives ${ }^{91}$; el 1453, els igualà també a aquests oficials en la capacitat de fer executar penalitats contra els que no obeïssin els seus manaments i sentències ${ }^{92}$.

\section{Els defensors de la mercaderia}

Foren representants de l'estament mercantil a les ciutats i viles marítimes. Ja hem comentat el privilegi concedit per Joan I, el 1394, als cònsols del mar de Barcelona per a elegir un consell assessor de deu a vint mercaders i per a donar poders a dos d'ells perquè s'ocupessin de la defensa del comerç ${ }^{93}$. El Parlament de Tortosa del 1400 estengué aquesta nova magistratura a totes les ciutats i viles marítimes i la dotà amb poders amplíssims per a organitzar flotes contra els corsaris -a fi de protegir el comerç- i per a encarregar-se, durant tres anys, de la defensa de les places catalanes a Sardenya, considerades refugi de corsaris i causa de la inseguritat marítima que afectava greument el comerç català. Durant aquest temps, el Parlament de Tortosa del 1400 els alliberà de tota jurisdicció superior, fins $i$ tot de la del rei i del primogènit. Per a finançar els seus objectius pogueren disposar d'un impost, el del pariatge, que gravà el comerç i el transport marítim ${ }^{94}$. Durant tot el segle XV fou una corporació molt influent.

\section{Ibidem, doc. 341.}

92 Ibidem, doc. 370.

93 C. CARRÈRE, Barcelone, l, pp. 52 i ss. Cf. abans, la nota 67.

94 M.T. FERRER I MALLOL, Els corsaris castellans i la campanya de Pero Niño al Mediterrani. Documents sobre el "Victorial", "Anuario de Estudios Medievales», 5 (1968), pp. 268-272; La conquesta de Sardenya i la guerra de cors mediterrània, a Els catalans a Sardenya, Barcelona, 1984, pp. 35-40; Barcelona i la política mediterrània catalana: el Parlament de 1400-1401, "XIV Congresso di Storia della Corona d'Aragona (Sassari-Alghero, 1990). II. La Corona d'Aragona in Italia (secC. XIII-XVIII). 1. II «regnum Sardiniae et Corsicae" nell'espansione mediterranea della Corona d'Aragona, Sassari, C. Delfino ed., 1995, pp. 427-443. 
També els consellers de Barcelona, amb el suport del Consell de Cent, tingueren autoritat en diversos afers marítims. Les seves principales atribucions foren les de nomenar els cònsols d'Ultramar, que representaven els interessos dels mercaders i navegants catalans en els països estrangers ${ }^{95}$, decidir la construcció de galeres de la ciutat i armar-les per a la defensa de la costa; en aquestes ocasions solien demanar privilegis reials que aprovessin l'elecció dels capitans de les seves galeres, amb plena jurisdicció civil i criminal sobre els tripulants, i que els eximissin, a vegades, del pagament del quint reial de les preses ${ }^{96}$.

Els consellers podien també dictar ordinacions sobre la navegació; per exemple, el 1458 disposaren que cap vaixell no sortís de Barcelona cap a Llevant o cap a Ponent sense navegar de conserva amb un altre i sense prestar les seguretats acostumades als cònsols de la mar ${ }^{97}$. Els consellers $i$ els cònsols envaïen així un terreny que abans pertocava al batlle general i que compartien amb ell en ocasions des de feia temps. El 1357, per exemple, per tal de solucionar les dificultats d'interpretació de les ordinacions reials sobre la navegació, amb què topaven el batlle general i el vicealmirall Guillem Morey, que eren els encarregats de fer-les observar, el rei Pere el Cerimoniós disposà

95 A. DE CAPMANY, Memorias, I, pp. 365-366; A. LÓPEZ DE MENESES, Los consulados catalanes de Alejandria y Damasco en el reinado de Pedro el Ceremonioso, «Estudios de Edad Media de la Corona de Aragón», VI (1956), pp. 83-183 i IDEM, Un siglo del Consulado de los Catalanes en Alejandria (1416-1516), a IX Congresso di Storia della Corona d'Aragona, (Nàpols, 1973). La Corona d'Aragona e il Mediterraneo: aspetti e problemi comuni da Alfonso il Magnanimo a Ferdinando il Cattolico (1416-1516), II, Nàpols, 1982, pp. 225-242. P. VOLTES i V. VILLACAMPA, Repertorio de documentos referentes a los cónsules de Ultramar y al Consulado de mar, conservados en el Instituto Municipal de Historia de Barcelona, "Documentos y Estudios», XIII. Aportaciones a la Historia Económica y Social de la Ciudad, 1964, pp. 21-165; J. F. CABESTANY, "Cònsols de Mar" y "Cònsols d'Ultramar en CataIuña (siglos XIII-XV), a Le genti del mare Mediterraneo, I, Nàpols, 1981, pp. 397-425; C.F. ROHNE, The origins and development of the catalan consulados ultramarinos from the thirteenth to the fifteenth centuries, University of Southern California, Ph D. 1966, ed. facs., Ann-Arbor University Microfilm International, Michigan, 1983. M.T. FERRER, Sobre els origens del Consolat de Mar el 1279 i sobre els consols d'Ultramar, pp. 144-150. R. SALICRÚ I LLUCH, Notes sobre el consolat de catalans a Siracusa (1319-1528), "XIV Congresso di Storia della Corona d'Aragona (Sassari-Alghero, 1990). La Corona d'Aragona in Italia (secc. XIII-XVIII). 2. Presenza ed espansione della Corona d'Aragona in Italia, vol, terzo, Sassari, C. Delfino ed., 1996, pp. 691-712. R. SAINZ DE LA MAZA LASOLI, // consolato dei Catalani a Pisa durante il regno di Giacomo /l d'Aragona. Notizie e documenti, "Medioevo. Saggi e Rassegne», 20 (1996), pp. 195-222; J. MUTGÉ VIVES, I Consell di Barcellona nell'ambito della politica siciliana di Giacomo /l d'Aragona, ibídem, pp. 223-250. J. MUTGÉ VIVES, Projecció de Barcelona en l'àmbit peninsular. Noticies sobre el consolat de catalans a Sevilla 1282-1327, a El municipi de BarceIona i els combats pel govern de la Ciutat, Ajuntament de Barcelona, Barcelona, Ed. Proa, 1997, pp. 29-38.

96 A. de CAPMANY, Memorias, II, docs. 16, 91 i 136.

97 Ibídem, doc. 376. Sobre la navegació de conserva cf. M.T. FERRER I MALLOL, La navegació de conserva a l'Edat Mitjana, «Anuario de Estudios Medievales», 24 (1994), pp. 453-464. 
que, si es tractava de vaixells de Barcelona o dels que havien arribat a la ciutat, els consellers de Barcelona decidissin en aquests $\operatorname{casos}^{98}$.

No hem d'oblidar tampoc que el terme de Barcelona es prolongava dins de mar dotze llegües marines; en aquest espai marí, els consellers hi tenien la mateixa jurisdicció que en el terme terrestre, on podien publicar bans o ordinacions sota qualsevol mena de multa o càstig, inclosa la pena capital ${ }^{99}$.

\section{Altres càrrecs}

Altres càrrecs mig reials mig municipals foren el del portolà, d'aparició tardana, a la segona meitat del segle $\mathrm{XV}$, creat segurament a imitació de la magistratura italiana i concretament siciliana, del mateix nom, bé que a Barcelona tingué, possiblement, una autoritat molt més reduïda. En sabem molt poca cosa, només que era un càrrec d'elecció municipal i que és esmentat per primera vegada el 1449. Havia de tenir cura dels pontons i de l'exacció del dret de l'ancoratge, imposat per a sufragar les despeses de la construcció del port de Barcelona ${ }^{100}$.

Cal mencionar també els guardes de Montjuïc i de Montgat que, a l'un extrem i l'altre del terme barceloní, tenien cura de la vigilància de la costa i el segon, a més, del far de Montjuïc ${ }^{101}$.

\section{Control de la navegació en temps de guerra}

Ja ens hem referit, quan hem tractat de les competències del batlle general, al control que exercia sobre la navegació en temps de guerra i sobre els armaments en cors, controls en els quals intervenien a vegades també altres autoritats. Ens referirem ara més àmpliament a ambdues qüestions.

El desenvolupament de la pirateria en gran escala durant els segles XIII i XIV obligà els estats marítims a controlar, tant com podien, l'armament de les naus dedicades al cors. El 1288, Alfons el Liberal disposà que els corsaris que armessin naus en els seus dominis lliuressin una fiança als oficials reials corresponents $i$ juressin no atacar els súbdits de països que estiguessin en pau o treva amb el rei ${ }^{102}$. Però no n'hi havia

98 Ibídem, II, doc. 177 i ACA, RP, Batllia, reg. 1056 (antiga classe 7ª H), f. 23 r. (1357, febrer, 18). Esmentat abans a nota 55

99 A. de CAPMANY, Memorias, II, doc. 104.

100 Sobre aquest càrrec, vegeu la breu nota de la seva elecció a J. VICENS I VIVES, Ferran II I la ciutat de Barcelona, Barcelona, Universitat de Catalunya, 1937, II, p. 295 i Apèndixs, p. 351, i J.F. CABESTANY I FORT i J. SOBREQUÉS I CALLICÓ, La construcció del port de Barcelona al segle $X V$, «Cuadernos de Historia Económica de Cataluña», VII , Barcelona, 1972, pp. 41-113 i especialment p. 52 .

101 Els pagaments a aquests funcionaris són nombrosos als registres de cartes del Batlle general, cf. per exemple: ACA, RP, Batllia, reg. 857 (antiga classe 7ạ, Ab, núm. 13), ff. 7 v., 23 v., 34 v.

102 A. de CAPMANY, Memorias, II, pp. 66-67. 
prou amb el control només dels vaixells dedicats al cors, era necessari controlar també els vaixells mercants. El seu armament, que la pirateria havia fet imprescindible per a qualsevol viatge llarg, donava ocasió a patrons i mercaders de convertir-se incidentalment en pirates ells mateixos quan les circumstàncies eren propícies. Hom queia, així, en un cercle viciós del qual era molt difícil sortir.

Els tractats de pau i aliança signats entre els diferents estats costaners del Mediterrani durant el segle XIV intentaren posar aturador a aquest problema. Si prenem com a exemple els tractats signats per la Corona catalano-aragonesa i Gènova, veurem que cadascuna de les parts es comprometé a prohibir els armaments de vaixells de rems, és a dir, de galeres, galiotes i llenys, usats per a la guerra, fora dels ports més importants - a Catalunya només el de Barcelona- on els oficials reials havien de rebre dels patrons fiances proporcionades al tonatge del vaixell, com també el jurament de no atacar els súbdits de nacions amigues. La fiança era no solament un instrument de coerció respecte als patrons sinó que era també un dipòsit per a indemnitzar les possibles víctimes. Les naus, coques, barques i en general els vaixells mercants armats estaven obligats a prestar el jurament, però no la fiança, llevat que es tinguessin sospites fundades que tenien intenció de sortir en cors. Com ja hem indicat, el batlle general fou l'encarregat de rebre aquestes fiances i de prendre el jurament. El rei quedà exceptuat d'aquestes restriccions portuàries en els armaments i quedà clar que podia armar per als seus afers on volgués ${ }^{103}$.

Les ordinacions marítimes de 1331 i $1333^{104}$, igual com les «Ordinacions reials sobre la manera de navegar en temps de guerra ${ }^{105}$, promulgades les primeres per Alfons el Benigne i les segones per Pere el Cerimoniós, en ocasió ambdues de la guerra contra Gènova, ofereixen la més àmplia informació sobre aquest particular. Les ordinacions de 1331-1333 imposaven l'armament dels vaixells, la navegació de conserva i altres precaucions semblants ${ }^{106}$. Les de Pere el Cerimoniós disposaven que cap vaixell, gros o petit, no pogués sortir de la platja de Barcelona o d'altres ports catalans sense llicència del consell reial resident a Barcelona, del batlle general o d'altres persones delegades per ells, exceptuats els vaixells que naveguessin entre Tortosa i Roses costejant i portant mercaderies de poc valor. Per a viatges més llargs o per al transport de mercaderies de valor, eren imprescindibles la llicència i l'armament del vaixell. Segons el tonatge es fixava a més la tripulació, que en època de guerra havia d'ésser més nombrosa. Els estrangers podien navegar lliurement per aigües catalanes i importar i exportar mercaderies, però no podien absolutament embarcar personal català ni prendre

103 M.T. FERRER I MALLOL, La pace del 1390 tra la Corona d'Aragona e la Repubblica di Genova, "Miscellanea di Storia Ligure in memoria di Giorgio Falco», Gènova, 1966, pp. 157 i ss. IDEM, Antecedenti e trattative per la pace del 1402.

104 J.M. MADURELL, Ordenanzas marítimas de 1331 y 1333, "Anuario de Historia del Derecho Español" (1961), pp. 611-628.

105 A. de CAPMANY, Ordenanzas de las armadas reales de la Corona de Aragón, aprobadas por el rey D. Pedro IV, año de MCCCLIV, Madrid, 1787, pp. 127-133, i Memorias, II, pp. 245-246.

106 M.T. FERRER I MALLOL, La navegació de conserva a l'Edat Mitjana, "Anuario de Estudios Medievales", 24 (1994), pp. 453-456. 
mercaderies de catalans, llevat que les portessin directament més enllà de l'Estret o que fossin la contrapartida de carregaments de gra o vitualles que els mercaders catalans haguessin fet venir amb aquests vaixells estrangers.

Aquesta darrera ordinació fou segurament el resultat de les negociacions del monarca amb els consellers de Barcelona com a representants dels interessos mercantils de la ciutat. Anteriorment, el 1353, el rei havia expedit ordres que restringien la navegació d'una manera molt més notable que en aquella ordinació. El mes de gener de 1353, havia prohibit la navegació pels mars catalans, llevat per al transport de vitualles, carbó, llenya, espart, palma i altres coses de poc valor o d'importància vital. La navegació a Ultramar havia estat limitada a les galeres armades, cosa que hauria produït, com podem suposar, un greu trastorn en les relacions comercials amb el Llevant, ja que les galeres eren escasses, solien ésser propietat d'entitats públiques -el rei, més tard la Generalitat de Catalunya, la ciutat de Barcelona etc.- i el transport que realitzaven resultava molt car, perquè necessitaven molt de personal i no podien portar molta càrrega. Pel febrer del mateix any la navegació fou completament suspesa davant la notícia que deu galeres genoveses estaven a punt de sortir de Gènova; només podia efectuar-se el transport de vitualles i altres coses necessàries per a la flota reial i encara prometent, sota fiança, abans de sortir, haver tornat abans del mes d'abril. Aquestes mesures havien de contrariar necessàriament els mercaders barcelonins, les activitats dels quals quedaven gairebé en suspens. Protestaren immediatament, però de moment no aconseguiren més que una declaració reial que posava a salvament els privilegis de la ciutat i les constitucions generals concedides per Pere el Gran, que no quedaven derogades per aquestes disposicions transitòries ${ }^{107}$.

Prohibicions semblants a les esmentades foren publicades freqüentment en el curs de les guerres amb Gènova i amb Castella, sempre amb la protesta dels barcelonins que, a vegades, n'aconseguiren l'anul-lació. Per exemple, el 9 de maig de 1356, el monarca autoritzà els barcelonins, malgrat les prohibicions recents, a transportar vitualles a Mallorca (llevat del blat, l'ordi i la civada, necessaris per a l'abastament de la mateixa Barcelona) ${ }^{108}$. Dos mesos més tard, el 16 de juliol, la navegació fou prohibida totalment altra vegada fins a nova ordre, davant la notícia que estava a punt de salpar de Gènova una flota de vint galeres ${ }^{109}$. Poques setmanes més tard, el 6 d'agost, aquesta ordre fou revocada per les protestes de Barcelona ${ }^{110}$. Pel mes d'octubre de 1359 , la navegació fou prohibida novament fins al mes d'abril següent, llevat que es prometés sota fiança haver retornat abans del dit mes; i altra vegada el 12 de novembre, a causa de la pressió de Barcelona, la prohibició hagué d'ésser moderada, donant-li més elasticitat pel que feia al termini de tornada; els consellers de Barcelona havien d'intervenir, a més, en la concessió de les llicències ${ }^{111}$.

\footnotetext{
107 A. de CAPMANY, Memorias, II, pp. 245-246.

108 A de CAPMANY, Memorias, II, pp. 261-262.

109 A. de CAPMANY, Ordenanzas, pp. 143-144.

110 A. de CAPMANY, Memorias, II, pp. 261-263.

111 A. de CAPMANY, Memorias, II, pp. 280-281.
} 
Tenim encara més notícies de restriccions imposades a la navegació barcelonina, el 1360, derogada el 8 d'octubre ${ }^{112}$, el 1363, amb derogació parcial, pel que feia a la navegació fins a Mallorca, el 2 de setembre ${ }^{113}$, i encara el 1369 , cosa que suscità la corresponent protesta dels barcelonins, que en aquestes ocasions apel.laven sempre al privilegi del «Recognoverunt Proceres», que els assegurava la lliure navegación ${ }^{114}$.

Com ja hem assenyalat més amunt, la decisió d'armar una flota per a defensar els regnes de la Corona catalano-aragonesa contra el duc d'Anjou, que pretenia tenir drets al regne de Mallorca, obligà el rei Pere el Cerimoniós a decretar, pel febrer de 1378, inhibició marítima general; quedà prohibit que les embarcacions petites sortissin de les mars catalanes i que les naus i els vaixells grossos s'allunyessin de l'àrea de la Mediterrània occidental, a fi que estiguessin disponibles quan el rei els necessités. La inhibició s'allargà durant un quant temps perquè, malgrat que les amenaces del duc d'Anjou no arribaren a concretar-se, l'esforç per a armar un estol continuà per tal de combatre la revolta dels Arborea a Sardenya i per a intervenir a Sicília, aprofitant que la successió havia recaigut en la jove reina Maria, néta de Pere el Cerimoniós. La llarga durada dels preparatius de l'estol, que no acabava mai d'estar a punt, obligà a concedir moltes excepcions; altrament, la vida econòmica se n'hauria ressentit molt ${ }^{115}$.

Durant el regnat de Joan I les prohibicions de navegar no foren tan freqüents, però tampoc no deixaren d'esser-hi. El 1393, en el moment en què Joan I preparava la flota per a sotmetre personalment la revolta de Sardenya, el monarca ordenà al consell reial resident a Barcelona que retingués al port totes les embarcacions fins a nova ordre i que es fes el mateix al llarg de tota la costa fins a Cotlliure, com també a Mallorca, a fi de poder ésser utilitzades en el moment oportú per al transport de cavalls; la mesura afectava tant els vaixells nacionals com els estrangers ${ }^{116}$.

Els exemples de restriccions a la navegació per causes polítiques o militars podrien multiplicar-se. No cal subratllar fins a quin punt hem de tenir en compte aquestes dades a l'hora d'estudiar el desenvolupament mercantil i marítim de Barcelona i d'assenyalar les èpoques de crisis, per tal de no confondre crisis passatgeres, lligades a determinades situacions militars o polítiques, amb crisis més profundes. De la mateixa manera, cal tenir en compte les possibles repercussions de les mesures de seguretat en la navegació - augment de l'armament i de la tripulació i major risc del viatge- en els costos dels transports.

112 J.F. CABESTANY, Repertorio, doc. 124.

113 J.F. CABESTANY, Repertorio, doc. 141

114 ACA, C, reg. 1227, f. 65 r.-v.

115 M.T. FERRER I MALLOL, La guerra d'Arborea alla fine del secolo XIV, en curs de publicació al volum de les Actes de «Giudicato d'Arborea e Marchesato di Oristano: proiezioni mediterranee e aspetti di storia locale. I Convegno Internazionale di Studi», Oristano, Istar, 1997.

116 ACA, C, reg. 1965, f. 175 r. Sobre aquesta expedició, cf. F. SOLDEVILA, Una nota su Giovanni I d'Aragona e la Sardegna, "Archivio Storico Sardo», XXIV (1954), pp. 425-435 i E. PUTZULU, La mancata spedizione di Giovanni l d'Aragona in Sardegna, Atti del VI Congresso internazionale di Studi Sardi, I, Cagliari, 1962, extret de $77 \mathrm{pp}$. 